\title{
Clinical and biochemical studies on treatment of Lesch-Nyhan syndrome
}

\author{
R. W. E. WATTS, R. O. MCKERAN, EDNA BROWN, T. M. ANDREWS, and \\ MARGARET I. GRIFFITHS \\ From the Division of Inherited Metabolic Diseases, M.R.C. Clinical Research Centre and Northwick Park \\ Hospital, Harrow, and the Department of Child Health, University of Birmingham
}

Watts, R. W. E., McKeran, R. O., Brown, E., Andrews, T. M., and Griffiths, M. I. (1974). Archives of Disease in Childhood, 49, 693. Clinical and biochemical studies on treatment of Lesch-Nyhan syndrome. The clinical findings in a previously unreported case of the Lesch-Nyhan syndrome are described. Though formal intellectual testing is very difficult because of the severe choreoathetosis and compulsive self mutilation, cognition appears to be less severely damaged than motor functions. It is most important to devise an active education programme for these children, and to control their self mutilation. Extracting all the teeth is strongly recommended from the latter point of view.

Replacing the deficient enzyme by means of exchange blood transfusion was associated with only a transient and small decrease of the serum uric acid level; the urinary uric acid excretion was not significantly altered. The blood levels of hypoxanthine-guanine phosphoribosyltransferase (HGPRT) had not decreased to about $10 \%$ of the mean normal range until 90 days after the transfusion.

The patient's motor state was not improved by any of the following. (i) Exchange blood transfusion; (ii) oral adenine and allopurinol; (iii) tetrabenazine; (iv) thiopropazate; (v) chlorpromazine. His scores in the Reynell Development Language scale tests improved during the 14-month period of observation, but the present evidence does not justify attributing this to any of the attempted treatments.

Some possible reasons for the apparent failure of transfusion to suppress purine synthesis or to improve the neurological disorder are discussed.

The present clear evidence that HGPRT-containing cells remain in the circulation in sufficient numbers to keep the HGPRT activity above $10 \%$ of the normal value for at least 90 days, suggests that it would still be justifiable to investigate a similar treatment in the neonatal period.

Gross deficiency of IMP: pyrophosphate phosphoribosyltransferase (EC 2.4.2.8) (hypoxanthine guanine phosphoribosyltransferase or HGPRT) activity is associated with choreoathetosis, compulsive self mutilation, aggressiveness, mental retardation, and a greatly increased rate of uric acid production with urinary stones and gout. The genetic data are compatible with $\mathrm{X}$-linked recessive inheritance. Lesch and Nyhan (1964) were the first to study the disorder in detail, though earlier published reports contain a few descriptions of clinically similar cases (Catel and Schmidt, 1959; Riley, 1960). The metabolic lesion was identified by Seegmiller, Rosenbloom, and Kelley (1967).

Received 26 February 1974.
The affected infants appear normal at birth, and the classical features of the syndrome develop in early childhood. Seegmiller et al. (1967) attributed the greatly accelerated rate of purine biosynthesis, and therefore of uric acid production, to reduced feedback inhibition by inosinic and guanylic acids (IMP and GMP) acting on the rate-limiting first specific reaction of de novo purine biosynthesis. This thesis has been generally accepted and implies a deficiency of these compounds presumably because the corresponding purine bases (hypoxanthine and guanine) are not conserved by the purine phosphoribosyltransferase reactions which are catalysed by HGPRT. The relevant metabolic inter-relations are summarized in Fig. 1.

There is no evidence that either hyperuricaemia 


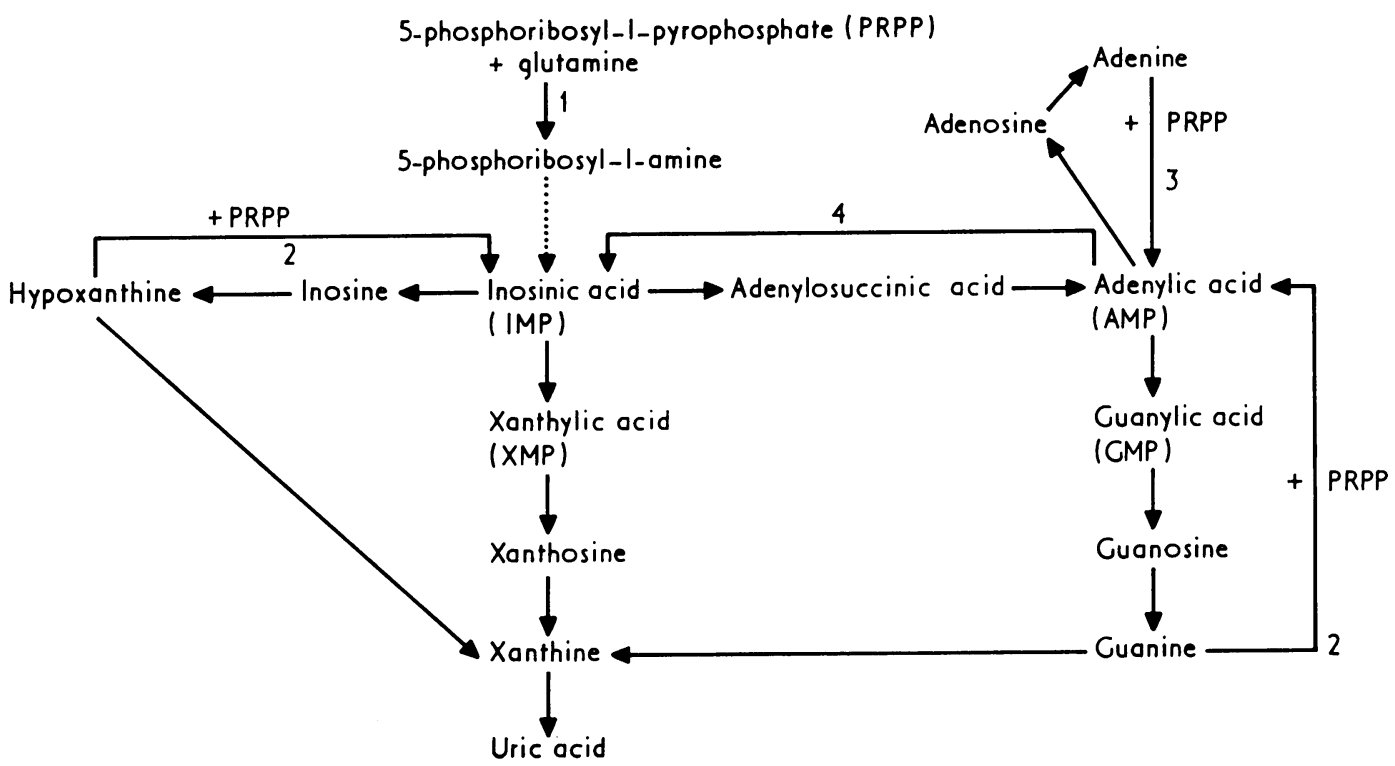

FIG. 1.-The metabolic inter-relations of de novo purine biosynthesis and the purine interconversion reactions. The broken arrow between 5-phosphoribosyl-l-amine and inosinic acid represents a series of biochemical reactions whereby the purine ring is built up. The enzymes which are particularly important with respect to the present work are as follows. 1, phosphoribosylpyrophosphate amidotransferase (EC 2.4.2.14); 2, hypoxanthine-guanine phosphoribosyltransferase (HGPRT) (EC 2.4.2.8); 3, adenine phosphoribosyltransferase (APRT) (EC 2.4.2.7); 4, AMP aminohydrolase (EC 3.5.4.6). Phosphoribosylpyrophosphate amidotransferase, which catalyses the first specific step on the de novo purine biosynthetic pathway, is subject to feedback inhibition by IMP, GMP, and AMP (Seegmiller et al., 1967; Caskey, Ashton, and Wyngaarden, 1964; Holmes et al., 1973).

or the increased CSF levels of hypoxanthine and xanthine which occur in the syndrome cause the neurological disorder. It seems more likely that they are due to lack of GMP, though the existence of an unidentified toxic factor cannot be positively excluded. Exogenous adenine could at least in theory be used for GMP synthesis because AMP: pyrophosphate phosphoribosyltransferase (EC 2.4.2.7) (adenine phosphoribosyltransferase or APRT) activity is present and increased in the patients and the metabolic pathways through inosinic and xanthylic acids (IMP and XMP) are available (Fig. 1). This idea received some support from the observations of Van der Zee, Schretlen, and Monnens (1968) who showed that the megaloblastic anaemia which exists in some cases of the Lesch-Nyhan syndrome can be cured by giving adenine. Felix and De Mars (1969) also showed that either additional adenine or high concentrations of folate were needed for the growth of fibroblasts from patients with the Lesch-Nyhan syndrome. It is of interest that Lommen et al. (1971) found normal erythrocyte GTP levels but low AMP, ADP, and ATP in 2 cases of the Lesch-Nyhan syndrome.
Oral adenine administration restored the adenine nucleotide concentration to normal and increased the GTP level slightly in their studies.

The renal complications and gout can be prevented by giving allopurinol, but this has no effect on the neurological manifestations even when it is given from birth. Attempts to counteract the disordered purine metabolism by giving AMP, GMP, guanosine, 2,6-diaminopurine, and adenine orally have produced no improvement, even though in one study (Schulman et al., 1971) adenine and allopurinol administration was begun immediately after birth. Orotic acid, which was given in an attempt to deplete the pool of 5'-phosphoribosylpyrophosphate (PRPP) available for the first specific step (Fig. 1) on the purine biosynthetic pathway (Seegmiller, 1968), also had no effect. The observation that glutamate produced some physical and neurological improvement (Ghadimi, 1969; Ghadimi, Bhalla, and Kirchenbaum, 1970) has not been substantiated except in so far as it was associated with improved nursing and general nutrition (Nyhan, 1972).

Enzyme replacement has not hitherto been 
attempted in the Lesch-Nyhan syndrome. This disorder appeared to offer an opportunity for such treatment because the missing enzyme could be given in the form of compatible erythrocytes without risk of immunological rejection. A useful therapeutic response might be expected if the neurological damage was due to a diffusable toxic factor requiring HGPRT for its metabolism. Similarly, the transfer of nucleotide or enzyme protein from transfused cells to the recipient's mutant cells by processes resembling metabolic co-operation (Subak-Sharpe, 1969) is at least a theoretical possibility. Erythrocytes transport purines from the tissues where they are synthesized to their sites of utilization, and the purine phosphoribosyltransferases effect the uptake of purines by these cells (Murray, 1971; Sperling et al., 1971; Adams and Harkness, 1973). Thus, purine transport between organs as distinct from intracellular transfer by metabolic co-operation would be expected to be impaired in the Lesch-Nyhan syndrome, and this would clearly be improved by the presence of normal cells in the circulation.

This paper reports (i) the effect of replacing the missing enzyme by means of exchange blood transfusions, (ii) our limited experience with adenine treatment, (iii) the results of attempts to regulate the involuntary movements and compulsive aggressive behaviour pharmacologically.

\section{Patient}

The patient was diagnosed as a case of the LeschNyhan syndrome when he was referred to one of us (M.I.G.) at the age of 3 years. A clinical diagnosis of the Lesch-Nyhan syndrome was confirmed by clinical chemical investigations at the Children's Hospital, Birmingham (urinary uric acid-creatinine ratio $4 \cdot 3$ ) and by demonstration of a deficiency of HGPRT by Dr. D. Orrell at the Group Pathology Laboratory, Warwick. He was referred (to R.W.E.W.) for further investigation and possible treatment at the M.R.C. Clinical Research Centre when he was aged 3 years 5 months.

Clinical history. The child is the second son of unrelated parents, his older brother being normal in all respects. The pregnancy was uneventful, but intrauterine movements were noticeably less vigorous than in the mother's first pregnancy. Delivery of a $3.57 \mathrm{~kg}$ infant was normal at term, the first stage lasting about 4 to 6 hours, the second stage less than half an hour, and the third stage being uncomplicated. Respiration started immediately and was maintained spontaneously. There was no neonatal jaundice, haemorrhagic diathesis, or subsequent respiratory difficulty. The mother noted that from birth his head would flop abnormally from side to side and back and forth when unsupported, 'as though it did not belong to him', and he was a generally 'floppy baby'. Both fists were usually firmly clenched and rarely opened.

The child sucked normally, was breast fed for 2 to 3 weeks and gained weight normally. He smiled at 6 to 7 weeks, and he recognized his mother at 6 weeks.

He could lift his head in the prone position at 3 months but severe motor retardation was apparent by 6 months and he has never been able to lift or support his trunk on outstretched hands. He has never crawled, walked, or been able to sit unsupported. He handled objects bimanually for the first time at 3 years and began to reach for things 3 months later. Choreoathetosis began at 12 months and, though of variable intensity, had progressively worsened to affect all four limbs. Opisthotonos was first observed at 9 months, and may occur during sleep. Spasticity of the legs, which was apparent at 2 years, improved with physiotherapy. He first vocalized at 6 months but his speech has always been slurred and his vocabulary poor.

At 18 months chronic ulcers on the buccal surface of his lips were the first sign of self inflicted trauma by biting. He also bit his fingers and this symptom with its attendant agitation and anxiety was relieved by bandaging his hands, but persistent lip biting has required total dental extraction. The lips have healed with minimal scarring, but he occasionally beats his head against objects or picks his nose until it bleeds, showing a persistent urge to self mutilation.

Past medical history. Bronchitis and measles without encephalitis. Tracheal stenosis was noted when he was anaesthetized for dental extraction.

Family history. The family pedigree is shown in Fig. 2. There is no history suggestive of gout, urolithiasis, or neuropsychiatric illness in any of the members, and no evidence for transmission of the mutant $\mathrm{X}$-linked gene through female relatives on the maternal side. The uric acid and PRT activities for the immediate blood relations are shown in Table I.

Examination (at 3 years 5 months). A small, generally underdeveloped boy. Weight $10 \mathrm{~kg}$ (Fig. 3), height $84 \mathrm{~cm}$ (these are both below the 3rd centile for his sex and age, the weight having been first recorded as $<3$ rd centile at 1 year 7 months). Head circumference $48 \mathrm{~cm}$. He scored at the 1.4-1.5 year level on the Reynell Developmental Language Scales and at the $2 \cdot 3$ year level on the Verbal Comprehension Scale 'B'. The eyes and optic fundi were normal. There was a slurring dysarthria with a monosyllabic 7 -word vocabulary, very occasional choreiform movements of the face and mouth, a generalized hypotonia and weakness. The legs were held adducted, and internally rotated at the hips, often crossed, with feet inverted and plantar flexed. Marked choreoathetoid movements of the arms and legs were present with intermittent spasmodic opisthotonos. He could lift his head off a pillow when prone, and roll over; but he could not sit up, support his body on his hands, crawl or walk, and at the age of 4 years he still needs a harness to support him when sitting (Fig. 4). When 


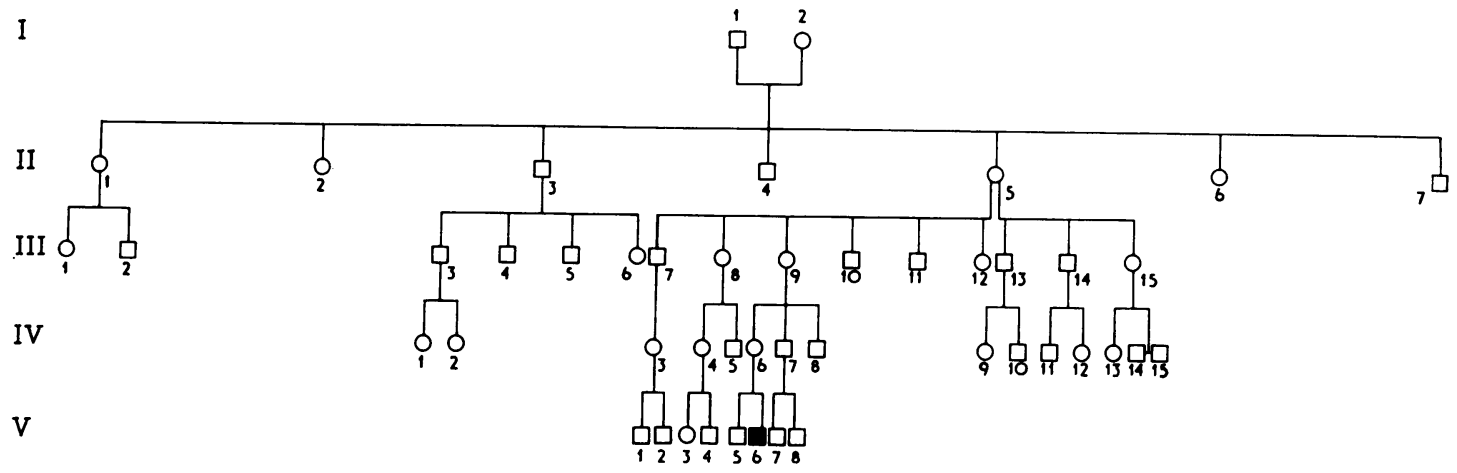

Fig. 2.-Pedigree chart. $\square$ patient.

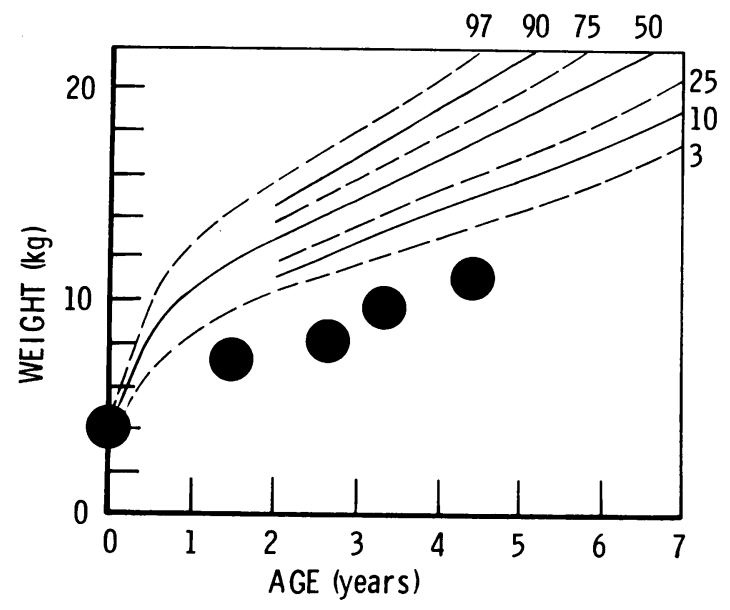

FIG. 3.-Weight chart of patient.

held unsupported the head flopped back or to one side, and exhibited maximal headlag when he was pulled up from the supine position. As far as could be judged, appreciation of pain and tactile sensation were normal. Reflexes were bilaterally symmetrical and not exaggerated. The plantar responses were extensor. The respiratory, cardiovascular, alimentary, and lymphatic systems were normal.

Blood pressure was $100 / 60 \mathrm{mmHg}$. Glycosuria and proteinuria were absent. Haemoglobin $13.3 \mathrm{~g} / 100 \mathrm{ml}$, erythrocyte indices normal, total leucocyte count $8200 / \mathrm{mm}^{3}$, differential leucocyte count normal, serum uric acid $536 \mu \mathrm{mol} / 1 .(9 \cdot 0 \mathrm{mg} / 100 \mathrm{ml})$, blood urea $5 \cdot 43$ $\mu \mathrm{mol} / \mathrm{l}$. (32 $\mathrm{mg} / 100 \mathrm{ml}$ ), serum sodium $139 \mathrm{mmol} / \mathrm{l}$., potassium $5.1 \mathrm{mmol} / 1$. , chloride $106 \mathrm{mmol} / \mathrm{l}$, bicarbonate $21 \mathrm{mmol} / \mathrm{l}$., calcium $2.39 \mathrm{mmol} / \mathrm{l}$, phosphate $1.47 \mathrm{mmol} / \mathrm{l}$., plasma total protein $70 \mathrm{~g} / \mathrm{l}$., albumin $47 \mathrm{~g} / 1$., total globulin $23 \mathrm{~g} / \mathrm{l}$., urinary uric acid $9 \cdot 4 \mathrm{mmol} / 1$. ( $(160 \mathrm{mg} / 100 \mathrm{ml})$, uric acid/creatinine ratio 3.2 (normal range $0.4-1.7$ at age 4 years, Kaufman, Greene, and Seegmiller, 1968). The urinary centrifuged deposit contained 'triple phosphate' cystals only, and was sterile on culture. He has a normal male chromosome pattern. Plain chest and skull $x$-rays and intravenous pyelogram were all normal. EEG showed no significant abnormality, medium voltage rhythmic activity (6-7 cycles/sec) being dominant and symmetrical in both hemispheres.

Biochemical observation on the proposidus

\begin{tabular}{|c|c|c|c|c|}
\hline \multirow{2}{*}{ Subject } & \multicolumn{2}{|c|}{ Plasma uric acid } & \multirow[b]{2}{*}{$(\mathrm{mmol} / \mathrm{l})}$. & 옴 \\
\hline & $(\mu \mathrm{mol} / 1)$. & $(\mathrm{mg} / 100 \mathrm{ml})$ & & $\begin{array}{c}(\mathrm{mg} / 100 \stackrel{\text { 䎡l }}{\mathrm{N}}) \\
\end{array}$ \\
\hline $\begin{array}{l}\text { Propositus ( } 3 \text { yr } 5 \mathrm{mth} \text { ) } \\
\text { Brother (5 yr) } \\
\text { Father } \\
\text { Mother } \\
\text { Maternal uncle (IV.7) } \\
\text { Maternal uncle (IV.8) } \\
\text { Maternal grandmother }\end{array}$ & $\begin{array}{l}536 \\
321 \\
380 \\
295 \\
410 \\
350 \\
362\end{array}$ & $\begin{array}{l}9 \cdot 0 \\
5 \cdot 4 \\
6 \cdot 2 \\
5 \cdot 0 \\
6 \cdot 9 \\
5 \cdot 9 \\
6 \cdot 1\end{array}$ & $\begin{array}{l}9 \cdot 52 \\
1 \cdot 25 \\
2 \cdot 60 \\
1 \cdot 73 \\
2 \cdot 74 \\
3 \cdot 92 \\
3 \cdot 54\end{array}$ & 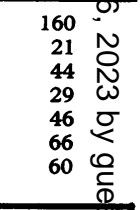 \\
\hline \multicolumn{5}{|c|}{ 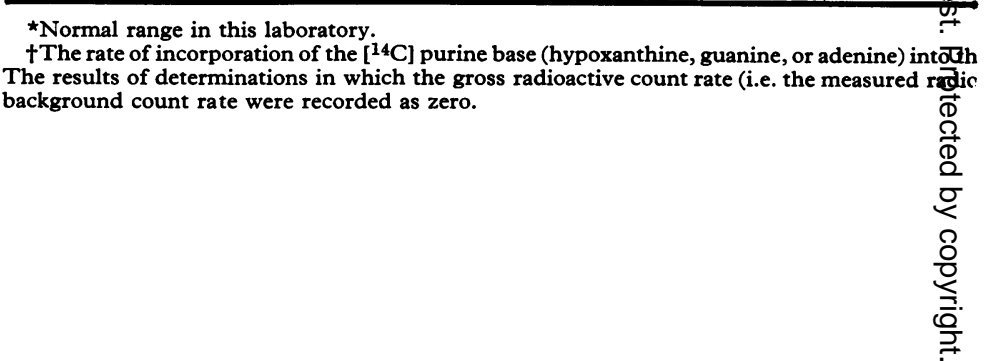 } \\
\hline
\end{tabular}




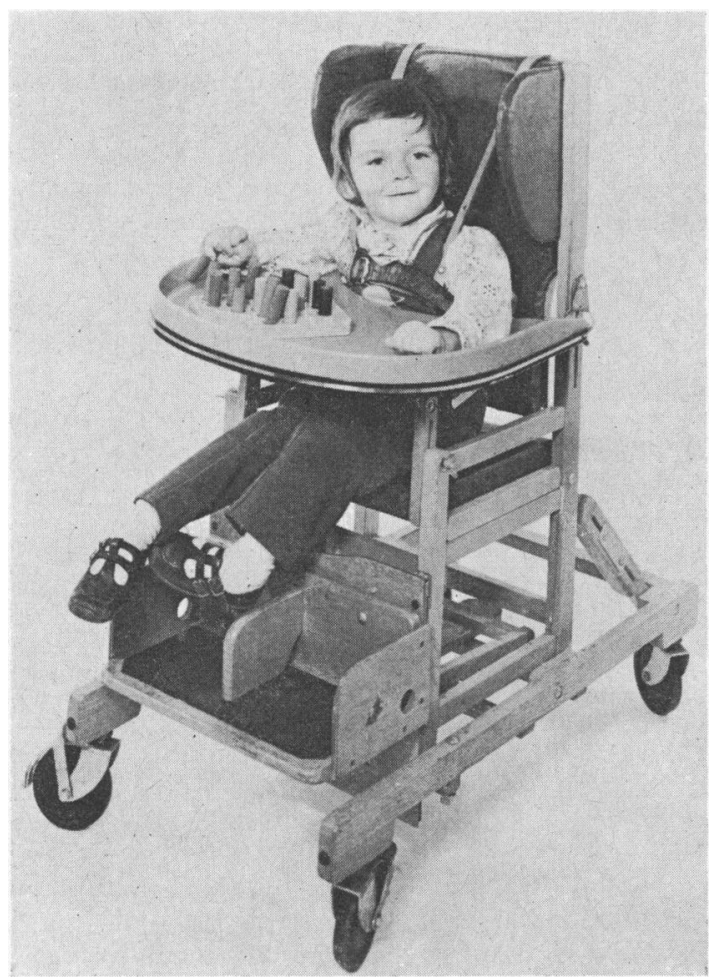

FIG 4.-The patient with harness for support.

Comparison of chronological and developmental ages. The patient's developmental age at different chronological ages was estimated on the basis of his mother's recollections using the criteria defined by Sheridan (1960). A significant degree of retardation was apparent from the age of 6 months, and this could be expected as an accompaniment of his severe motor handicap. The use of standard IQ tests was impossible because, in addition to the basic motor handicap, involuntary movements are exacerbated in conditions of stress, though it could be shown that expressive speech and language comprehension are slowly improving (Table II).

Assessment of severity of involuntary movements. The effect of drugs on the involuntary movements was evaluated clinically, and on the basis of the opinions of his mother, the play therapist, and the ward nursing and medical staff. The mother remained in hospital with the child for almost the whole of his stay, and she kept a record of his symptoms during the periods when he was at home. Attempts to measure the amount of involuntary movement (mainly pronation and supination) by means of movement counters which were modified self-winding wrist watches were abandoned. Such methods give no record of change in the quality, as opposed to the quantity, of the movements. Both continuous and time-lapse cinematographic recording were considered to be impracticable for such a long study during which marked spontaneous fluctuations in the quality as well as the quantity of the movements were to be expected.

Intermittent cinematographic recording was, however, used to assess the effect of the exchange transfusion. The same sequence of manipulative hand movements was filmed under identical conditions with respect to the surroundings, illumination, and people present. After a preliminary learning period, observations were made on days 15,8 , and 6 before, and on days $5,13,20,32,42,70$, and 118 after the transfusion. The films were randomized, scored by 15 different observers, and the following assessments made: (i) accuracy of reaching for a desired object (a Smartie sweet); (ii) ability to grasp the object; (iii) ability to bring the object to the mouth; (iv) the severity of any associated involuntary movements.

This work was approved by the Ethical Committee of Northwick Park Hospital and the M.R.C. Clinical Research Centre. The procedures, which were all designed to be therapeutic for the patient concerned, were fully explained to both parents and their formal consent was obtained.

ind on some of his immediate relatives

\begin{tabular}{|c|c|c|c|}
\hline ic acid & \multicolumn{3}{|c|}{$\begin{array}{c}\text { Blood cell PRT activity } \\
\text { (nmol/hr per mg protein) }\end{array}$} \\
\hline uric acid/creatinine) & $\begin{array}{c}\text { Hypoxanthine } \\
(81 \pm 22 ; \text { no. }=20)^{\star}\end{array}$ & $\begin{array}{c}\text { Guanine } \\
(87 \pm 16 ; \text { no. }=20)^{\star}\end{array}$ & $\begin{array}{c}\text { Adenine } \\
(14 \pm 3 ; \text { no. }=20)^{\star}\end{array}$ \\
\hline $\begin{array}{l}3 \cdot 2 \\
0 \cdot 55 \\
0 \cdot 37 \\
0 \cdot 37 \\
0 \cdot 27 \\
0.35 \\
0 \cdot 41\end{array}$ & $\begin{array}{l}0 \dagger \\
76 \\
74 \\
72 \\
71 \\
67 \\
69\end{array}$ & $\begin{array}{r}0 \\
86 \\
79 \\
74 \\
88 \\
69 \\
75\end{array}$ & $\begin{array}{l}32 \\
13 \\
14 \\
12 \\
13 \\
14 \\
13\end{array}$ \\
\hline
\end{tabular}




\section{Chemical methods}

The following analytical methods were used: uric acid (Liddle, Seegmiller, and Laster, 1959), creatinine (Bonsnes and Taussky, 1945), protein (Lowry et al., 1951); 2,8-dioxyadenine (Schulman et al., 1971); the purine phosphoribosyltransferases (HGPRT and APRT) (Seegmiller et al., 1967).

\section{Results}

The changes in the HGPRT and APRT levels which were associated with the exchange blood transfusion are shown together with blood and urine uric acid levels in Fig. 5. Manipulative skills and involuntary movements, assessed by serial filming
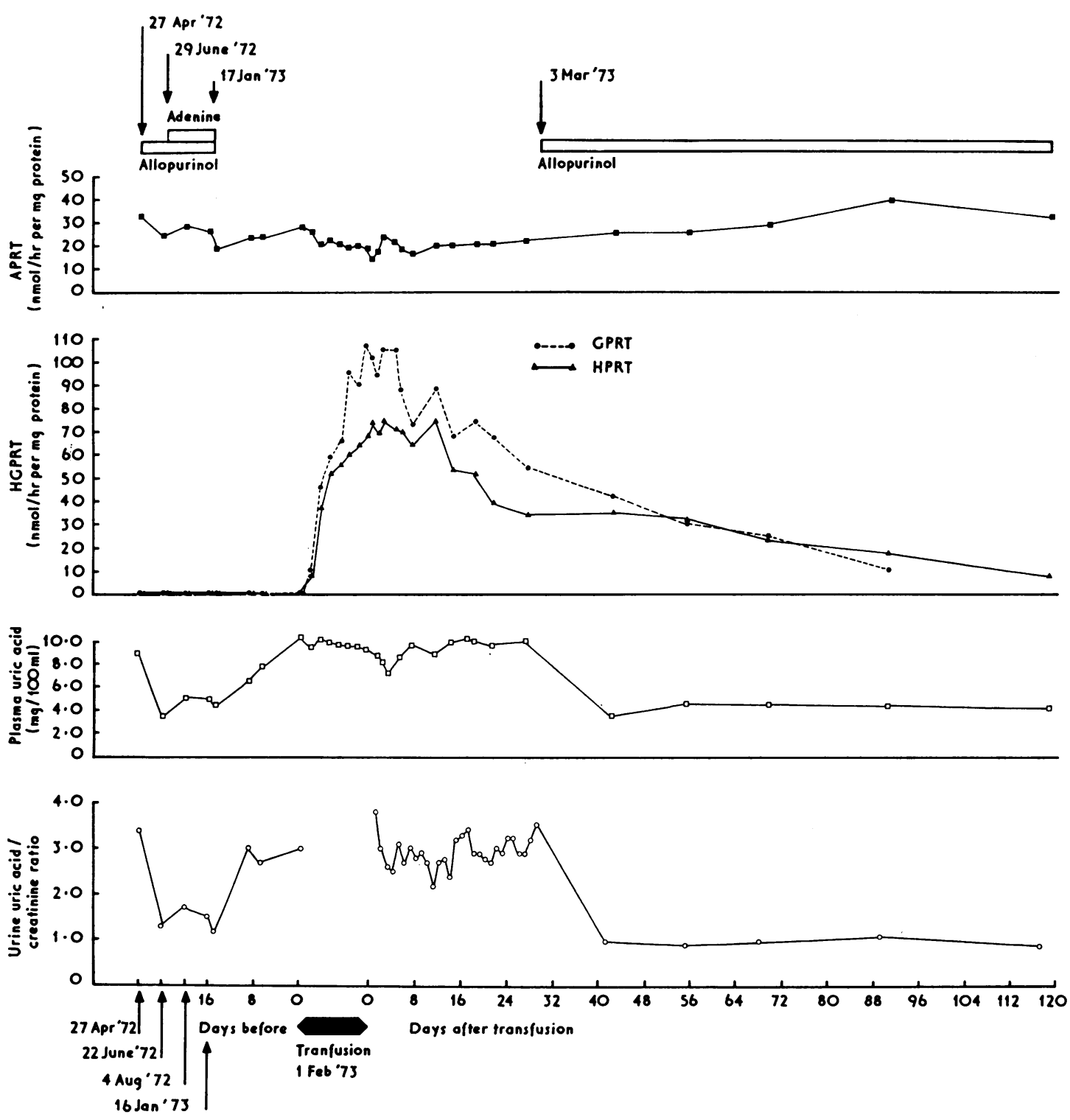

FIG. 5.-Changes in plasma and urinary uric acid, in blood cell HGPRT and APRT associated with a single exchange blood transfusion in a patient with the Lesch-Nyhan syndrome. 
TABLE II

Results of Reynell Development Language Scale Tests

\begin{tabular}{|c|c|c|c|c|c|}
\hline \multirow{2}{*}{ Date of test } & \multirow{2}{*}{ Chronological age (yr) } & \multicolumn{2}{|c|}{ Verbal comprehension scale $\mathbf{B}$} & \multicolumn{2}{|c|}{ Expressive language scale } \\
\hline & & Raw score & Age level (yr) & Raw score & Age level (yr) \\
\hline $\begin{array}{l}20 \text { May } 1972 \\
20 \text { Jan } 1973 \\
13 \text { July } 1973\end{array}$ & $\begin{array}{l}3 \cdot 4 \\
4 \cdot 1 \\
4 \cdot 6\end{array}$ & $\begin{array}{l}19 \\
28 \\
37\end{array}$ & $\begin{array}{l}2 \cdot 3 \\
2 \cdot 8 \\
3 \cdot 3\end{array}$ & $\frac{11}{25}$ & $\frac{1 \cdot 4-1 \cdot 5}{2 \cdot 4}$ \\
\hline
\end{tabular}

27 April '73

29 June 72

17 Jan $^{\circ} 73$

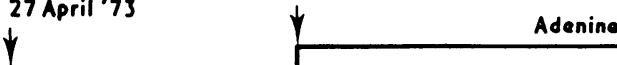

Allopurinol
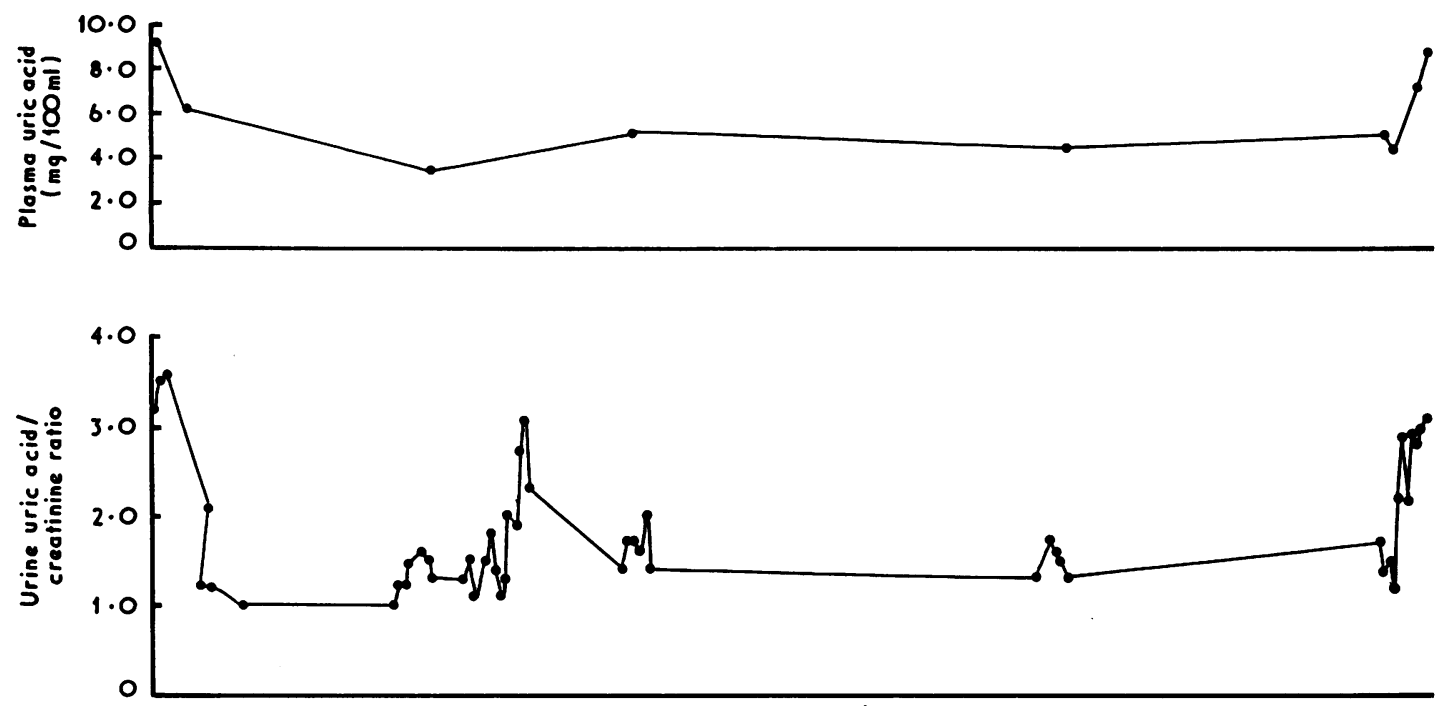

ô

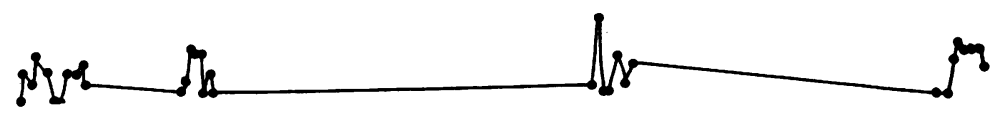

0.100

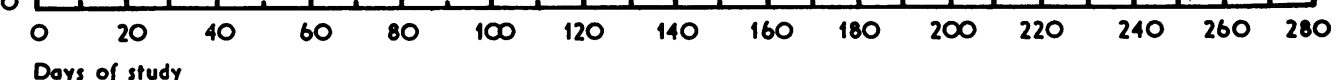

FIG. 6.--Plasma and urine uric acid, and urine 2,8-dioxyadenine levels during treatment with adenine and allopurinol 2,8-dioxyadenine is very insoluble in urine and could therefore cause urinary obstruction. It is formed by the xanthine oxygen oxidoreductase (xanthine oxidase, EC 1.2.3.2) catalysed oxidation of adenine, and this is prevented by the concurrent administration of allopurinol. 
and ward observation were not detectably improved. Similarly, the pattern of compulsive behaviour and overall intelligence as judged clinically and psychometrically were not improved specifically in relation to the transfusion. Plasma and urine uric acid concentrations, and urine 2,8-dioxyadenine levels during allopurinol and adenine treatment are shown in Fig. 6. There were no striking changes in the patient's behaviour during this period.

Neither tetrabenazine $(5 \mathrm{mg}$ twice daily for 1 month) nor thiopropazate $(1.25 \mathrm{mg}$ daily for 1 month) had any effect on the involuntary movements or behaviour. Chlorpromazine ( $5 \mathrm{mg}$ three times daily for several months) produced an overall depression of activity with drowsiness.

\section{Discussion}

The clinical features of this case conform to those described by Lesch and Nyhan (1964), and to the cases which have been reported by other workers (Kelley and Wyngaarden, 1972). The present case appears to have been hypotonic from birth, a feature which has not usually been reported in the LeschNyhan syndrome (Nyhan, 1973). Hypotonia in infancy may be due to a variety of causes (Dubowitz, 1969; Griffiths, 1973). It frequently precedes the choreoathetotic forms of cerebral palsy caused by kernicterus or by severe anoxia in the perinatal period (often in term infants). Such children show a wide range of intelligence, though their choreoathetosis is never associated with the self mutilation characteristic of the Lesch-Nyhan syndrome.

Prechtl (1971) emphasized the importance of cerebral maturation in the development of early motor skills. It is also clear that early interference with motor function may limit a child's development in a manner disproportionate to the degree of intellectual impairment. In a child with the Lesch-Nyhan syndrome the urge to self mutilation also impairs his ability to respond to stimuli from the environment, and in our patient the improved response after the final dental extraction was striking. The development of choreoathetosis in the present case did not differ substantially from the progression seen in children with cerebral palsy and it was the self mutilation and lack of any perinatal factors in the history which suggested the diagnosis.

The last trimester of pregnancy and the first 18 months of postnatal life are the periods during which the human brain is most vulnerable to factors (e.g. nutritional and endocrine deficiencies) which impair growth, this being unrelated to teratogenic susceptibility (Dobbing, 1972). Nervous tissue, like bone marrow, depends largely on the purine salvage pathway as opposed to the de novo synthesis pathway (Fig. 1) for purine ribonucleotide synthesis (Lajtha and Vane, 1958; Howard, Kerson, and Appel, 1970). Besides catalysing the direct formation of IMP and GMP for intracellular functions, HGPRT regulates the rate of purine uptake by cells (Berlin and Stadtman, 1966; Gots, 1971) and is needed for the transport of purines by erythrocytes (Murray, 1971; Sperling et al., 1971; Adams and Harkness, 1973). Thus, congenital HGPRT deficiency may reduce intracellular GMP to levels which are rate-limiting for protein or nucleic acid synthesis at a time when this is critical for the rapid division and maturation of brain cells. The reported differences in the HGPRT activities in different regions of the brain are small, and need not necessarily reflect different enzyme activities within neurones or neuroglia. The largest difference, which is that seen between basal ganglia and the cerebral cortex is only twofold (Kelley et al., 1969). This apparent difference may be further diminished when account is taken of the $5^{\prime}$ nucleotidase ( $5^{\prime}$ ribonucleotide phosphohydrolase EC 3.1.3.5) activity in different parts of the brain (Adams et al., 1971; Adams, 1973). Factors other than the absolute levels of HGPRT may be important in determining the evolution of brain damage in the Lesch-Nyhan syndrome. Regional differences in, for example, the rate of neuronal development and biochemical differentiation during prenatal and early postnatal life, with earlier dependence on purine salvage pathways in the basal ganglia may influence the final pattern of brain damage.

Patients with partial deficiency of HGPRT have between about 0.05 and $10 \%$ of the normal level of enzyme in erythrocytes, gross hyperuricaemia, hyperuric aciduria, gout, uric acid, and urate nephropathies, with at the most, only minor neuropsychiatric damage (Kelley et al., 1969). Increasing the present patient's circulating level of HGPRT to well above the range of values quoted by Kelley et al. (1969) did not influence the neuropsychiatric state and produced only a transient small decrease in the plasma urate concentration (Fig. 4). This is compatible with the observations of Emmerson and Thompson (1973) that the clinical severity over the whole spectrum of neurological disability did not parallel the degree of erythrocyte HGPRT deficiency.

The absence of any observable effect on the neurological signs may reflect irreversible perinatal brain damage, and examination of the brains of older children has shown microcephaly and minor histological changes (Crome and Stern, 1972). It appears that though motor functions may already be 
impaired at birth, significant cognitive development can still be expected. An intelligent athetoid child can often be trained to overcome his disabilities and to use mechanical aids, whereas much less can be accomplished with the mentally retarded disabled patient. Thus, every effort should be made to exploit the apparent differential impairment of intellectual and motor manifestations in the Lesch-Nyhan syndrome with as full an educational programme as the patient's physical disabilities allow.

It has been widely accepted that the high rate of purine biosynthesis in the Lesch-Nyhan syndrome is due to decreased feedback inhibition by GMP and/or IMP of the first specific reaction on the pathway of de novo purine biosynthesis (Seegmiller et al., 1967). This hypothesis is not amenable to direct experimental proof in vivo though the kinetic properties in vitro of the relevant enzyme* isolated from human placenta are compatible with this suggestion (Holmes et al., 1973). If the proposition of Seegmiller et al. (1967) is correct, our failure to influence uric acid levels in the blood and urine by transfusion with normal red cells must be due to one or more of the following factors. (i) The inability to introduce enough normal enzyme to increase the supply of GMP and/or IMP significantly; (ii) failure of GMP and/or IMP to cross cell membranes and reach the phosphoribosylpyrophosphate amidotransferase; (iii) an absolute requirement for HGPRT within recipient tissue cells to effect purine uptake and to catalyse the synthesis of GMP and IMP in a co-ordinated manner, as part of a single integrated cellular function. Similar considerations could apply to our failure to alter neuronal function.

The possible importance of an unidentified toxic factor in the aetiology of the Lesch-Nyhan syndrome has been stressed (Nyhan, 1973). Our failure to influence neural function argues against there being a diffusable toxic factor, the production or metabolism of which can be modified by HGPRT in circulating erythrocytes, unless the brain damage is already irreversible by the age of $3 \frac{1}{2}$ years. We consider that, in spite of these negative results, and though the scope for improvement in motor function may be small, it would be justifiable to explore exchange-transfusion in a neonatal case, aiming to keep a circulating level of HGPRT above about $10 \%$ of the normal average value for the first 2 or 3 years of life. The present findings indicate that exchange transfusions of normal erythrocytes would be necessary about every 100 days.

\footnotetext{
*[Ribosylamine-5-phosphate : pyrophosphate phosphoribosyltransferase (glutamate-amidating) (EC 2.4.2.14)] or phosphoribosyl pyrophosphate amidotransferase.
}

Our results with adenine and allopurinol therapy are the same as those of most other investigators. Adenine has now been tried unsuccessfully in several centres (Van Der Zee et al., 1970; Schulman, et al., 1971; and the present study) and in the absence of any clear effect on the neurological state, its use is not recommended except for the treatment of the megaloblastic anaemia. Conversely, Demus, Kaiser, and Schaub (1973) thought that their patient was improved by adenine, but they were unable to continue giving it because of nephrotoxicity. The latter is due to the xanthine oxidase-catalysed oxidation of adenine to 2,8-dioxyadenine and can be avoided by giving allopurinol simultaneously with the adenine, as in the present work.

Our attempts to ameliorate choreoathetosis with tetrabenazine, thiopropazate, and chlorpromazine were unsuccessful, and these drugs cannot be recommended as having any specific role in the management of patients with the Lesch-Nyhan syndrome. Conversely, it is essential to give allopurinol in order to protect the urinary tract and to prevent the development of gout.

It is of interest that Bakay and Nyhan (1972) found that the variant type of HGPRT enzyme which is associated with the Lesch-Nyhan syndrome is activated by the normal enzyme in vitro. The present results show that this cannot be achieved when the two proteins are in separate and noncontiguous cells. New lines of treatment may stem from the recent evidence that erythrocytes from patients with the Lesch-Nyhan syndrome contain normal amounts of HGPRT protein, which is, however, abnormally labile in vivo. Thus, if the enzyme could be stabilized, its activity might be restored (Arnold, Meade, and Kelley, 1972). The present work suggests that it would be necessary to stabilize the enzyme in the tissues generally and not only in the blood.

We acknowledge our indebtedness to Dr. M. Liberman, who performed the exchange blood transfusion; to our other paediatric colleagues; and to $\mathrm{Mr}$. Heinz Wolff (C.R.C. Bioengineering Division) and Mr. R. Bowlby (C.R.C. Medical Illustration Department) for their advice on recording methods. We are also indebted to our colleagues in clinical chemistry and paediatrics at the Birmingham Children's Hospital for their help.

\section{REFERENCES}

Adams, A. (1973). The development, distribution and properties of purine phosphoribosyltransferases in mammals. Ph.D Thesis. University of Edinburgh.

Adams, A., Anderson, J. M., Nicol, A. D., and Harkness, R. A. (1971). The development of hypoxanthine/guanine phosphoribosyltransferase activity in man. Biochemical fournal, 125, $36 \mathrm{P}$. 
Adams, A., and Harkness, R. A. (1973). Purine uptake from erythrocytes by rabbit tissues in vivo. Biochemical Society Transactions, 1, 138.

Arnold, W. J., Meade, J. C., and Kelley, W. N. (1972). Hypoxanthineguanine phosphoribosyltransferase: characteristics of the mutant enzyme in erythrocytes from patients with the Lesch-Nyhan syndrome. fournal of Clinical Investigation, 51, 1805.

Bakay, B., and Nyhan, W. L. (1972). Activation of variants of hypoxanthineguanine phosphoribosyltransferase by the normal enzyme. Proceedings of the National Academy of Sciences of the U.S.A., 69, 2523.

Berlin, R. D., and Stadtman, E. R. (1966). A possible role of purine nucleotide pyrophosphorylases in the regulation of purine uptake by Bacillus subtillis. Fournal of Biological Chemistry, 241, 2679.

Bonsnes, R. W., and Taussky, H. H. (1945). On the colorimetric determination of creatinine by the Jaffe reaction. fournal of Biological Chemistry, 158, 581.

Caskey, C. T., Ashton, D. M., and Wyngaarden, J. B. (1964). The enzymology of feedback inhibition of glutamine phosphoribosylpyrophosphate amidotransferase by purine ribonucleotides. fournal of Biological Chemistry, 239, 2570.

Catel, W., and Schmidt, J. (1959). Úber familiäre gichtische Diathese in Verbindung mit zerebralen und renalen Symptomen bei einem Kleinkind. Deutsche Medizinische Wochenschrift, 84, 2145.

Crome, L., and Stern, J. (1972). Pathology of Mental Retardation, 2nd ed. Churchill Livingstone, Edinburgh and London.

Demus, A., Kaiser, W., and Schaub, J. (1973). The Lesch-Nyhan syndrome. Metabolic studies during administration of adenine. Zeitschrift für Kinderheilkunde, 114, 119.

Dobbing, J. (1972). Vulnerable periods of brain development. In Symposium on Lipids, Malnutrition and the Developing Brain. Ed. by K. Elliott and J. Knight. A Ciba Foundation Symposium jointly with the Nestle Foundation in memory of Sir Norman Wright. Elsevier, Amsterdam.

Dubowitz, V. (1969). The Floppy Infant. Heinemann, London.

Emmerson, B. T., and Thompson, L. (1973). The spectrum of hypoxanthineguanine phosphoribosyltransferase deficiency. Quarterly fournal of Medicine, 42, 423.

Felix, J. S., and De Mars, R. (1969). Purine requirement of cells cultured from humans affected with Lesch-Nyhan syndrome (Hypoxanthine-guanine phosphoribosyltransferase deficiency). Proceedings of the National Academy of Sciences of the U.S.A., $62,536$.

Ghadimi, H., Bhalla, C. K., and Kirchenbaum, D. M. (1970). The significance of the deficiency state in Lesch-Nyhan disease. Acta Paediatrica Scandinavica, 59, 233.

Gots, J. S. (1971). Regulation of purine and pyrimidine metabolism. In Metabolic Pathways, 3rd ed., Vol. 5. Metabolic Regulation. Ed. by H. J. Vogel. Academic Press, New York.

Griffiths, M. I. (1973). Special handicaps: motor disability. In The Young Retarded Child. Medical Aspects of Care, p. 103. Churchill Livingstone, London and Edinburgh.

Holmes, E. W., McDonald, J. A., McCord, J. M., Wyngaarden, J. B., and Kelley, W. N. (1973). Human glutamine phosphoribosylpyrophosphate amidotransferase. Kinetic and regulatory properties. Fournal of Biological Chemistry, 248, 144.

Howard, W. J., Kerson, L. A., and Appel, S. H. (1970). Synthesis de novo of purines in slices of rat brain and liver. fournal of Neurochemistry, 17, 121.

Kaufman, J. M., Greene, M. L., and Seegmiller, J. E. (1968). Urine uric acid to creatinine ratio-a screening test for inherited disorders of purine metabolism. Journal of Pediatrics, 73, 583.
Kelley, W. N., Greene, M. L., Rosenbloom, F. M., Henderson, J. F., and Seegmiller, J. E. (1969). Hypoxanthine-guanine phosphoribosyltransferase deficiency in gout. Annals of Internal Medicine, 70, 155.

Kelley, W. N., and Wyngaarden, J. B. (1972). The Lesch-Nyhan syndrome. In The Metabolic Basis of Inherited Disease, 3rd ed., p. 969 . Ed. by J. B. Stanbury, J. B. Wyngaarden, and D. S. Fredrickson. McGraw-Hill, New York.

Lajtha, L. G., and Vane, J. R. (1958). Dependence of bone marrow cells on the liver for purine supply. Nature, 182, 191.

Lesch, M., and Nyhan, W. L. (1964). A familial disorder of uric acid metabolism and central nervous system function. American fournal of Medicine, 36, 561.

Liddle, L., Seegmiller, J. E., and Laster, L. (1959). Enzymatic spectrophotometric method for determination of uric acid. fournal of Laboratory and Clinical Medicine, 54, 903.

Lommen, E. J. P., Vogels, G. D., Van der Zee, S. P. M., Trijbels, J. M. F., and Schretlen, E. D. A. M. (1971). Concentration of purine nucleotides in erythrocytes of patients with the LeschNyhan syndrome before and during oral administration of adenine. Acta Paediatrica Scandinavica, 60, 642.

Lowry, O. H, Rosebrough, N. J., Farr, A. L, and Randall, R. J. (1951). Protein measurement with the Folin phenol reagent. fournal of Biological Chemistry, 193, 265.

Murray, A. W. (1971). The biological significance of purine salvage. Annual Review of Biochemistry, 40, 811.

Nyhan, W. L. (1972). Clinical features of the Lesch-Nyhan syndrome. Archives of Internal Medicine, 130, 186.

Nyhan, W. L. (1973). The Lesch-Nyhan syndrome. Annual Review of Medicine, 24, 41.

Prechtl, H. F. R. (1971). Motor behaviour in relation to brain structure. In Normal and Abnormal Development of the Brain and Behaviour, p. 133. Ed. by G. B. A. Stoelinga, and J. J. van der Werff ten Bosch. University Press, Leiden.

Riley, I. D. (1960). Gout and cerebral palsy in a three-year-old boy. Archives of Disease in Childhood, 35, 293.

Schulman, J. D., Greene, M. L., Fujimoto, W. Y., and Seegmiller, J. E. (1971). Adenine therapy for Lesch-Nyhan syndrome. Pediatric Research, 5, 77.

Seegmiller, J. E. (1968). Seminars on Lesch-Nyhan syndrome. Management and treatment. Federation Proceedings, 27, 1097.

Seegmiller, J. E., Rosenbloom, F. M., and Kelley, W. N. (1967) Enzyme defect associated with a sex-linked human neurological disorder and excessive purine synthesis. Science, 155, 1682.

Sheridan, M. D. (1960). The developmental progress of infants and young children. In Ministry of Health Reports on Public Health and Medical Subjects, No. 102. H.M.S.O., London.

Sperling, O., Ellam, G., Schmidt, R., Mundel, G., and De Vries, A. (1971). Purine base incorporation into erythrocyte nucleotides in hypoxanthine-guanine phosphoribosyltransferase deficiency. Biochemical Medicine, 5, 173.

Subak-Sharpe, J. H. (1969). Metabolic co-operation between cells. In Homeostatic Regulators. Ciba Foundation Symposium. Edited by G. E. W. Wolstenholme. Churchill, London.

Van der Zee, S. P. M., Lommen, E. J. P., Trijbels, J. M. F., and Schretlen, E. D. A. M. (1970). The influence of adenine on the clinical features and purine metabolism in the Lesch-Nyhan syndrome. Acta Paediatrica Scandinavica, 59, 259.

Van der Zee, S. P. M., Schretlen, E. D. A. M., and Monnens, L. A. H. (1968). Megaloblastic anaemia in the Lesch-Nyhan syndrome. Lancet, 1, 1427.

Correspondence to Dr. R. W. E. Watts, Division of Inherited Metabolic Diseases, Clinical Research Centre, Watford Road, Harrow, Middlesex HA1 3UJ. 